\title{
Retraction Note to: Structural, dielectric and electrical properties of cerium-modified strontium manganite ceramics
}

\author{
P. G. R. Achary ${ }^{1}$, Sonali Behera ${ }^{2}$, R. N. P. Choudhary ${ }^{2}$, and S. K. Parida ${ }^{2, \star}$ (I) \\ ${ }^{1}$ Department of Chemistry, Siksha O Anusandhan Deemed To Be University, Bhubaneswar, India \\ ${ }^{2}$ Department of Physics, Siksha O Anusandhan Deemed To Be University, Bhubaneswar, India
}

Published online:

30 September 2021

(C) Springer Science+Business

Media, LLC, part of Springer

Nature 2021

Retraction to: J Mater Sci: Mater Electron (2021)

32:5738-5754

https://doi.org/10.1007/s10854-021-05295-w

The editors have retracted this article. Following publication, a reader noted a number of substantial errors in Sects. 3.2 and 3.3, particularly the following:

1. X-ray diffraction patterns shown in Fig. 1a and $1 b$ are measured in the $2 \theta$-range from $10^{\circ}$ to $80^{\circ}$, while subsequent calculations suggest that the data are from $2 \theta$ values which are greater than $180^{\circ}$.

2. Errors in the quoted Scherrer formula should be written as $\cos \theta=(0.892 / D)(1 / \beta)$.

The original article can be found online at https:/ / doi.org/10.1007/s10854-021-05295-w.

Address correspondence to E-mail: santoshparida@soa.ac.in
3. Errors in the calculations after Fig. 2a included imprecise ranges on the vertical axis.

4. Errors in the slope of the approximation line result in negative values for the average size of the crystallites.

5. Errors in the plot presented in Fig. 2b.

6 Lack of correspondence between data presented in Fig. 2c. and SEM micrographs.

7. Highly unusual values on the agglomeration rate.

8. Errors in data presented in Table 1 suggest that the Rietveld refinement was not made contrary to the statement present in the text.

9 Incorrect use of the term "phase transition" when changing the composition of the crystal (hereby incorporation of Ce ions). 
As a result of these errors, the Editors no longer have confidence in the results and conclusions of this article. The authors have been invited to submit a revised manuscript for further peer review.

P.G.R. Achary and S.K. Parida agree with this retraction but not with the wording of this retraction notice. Sonali Behara and R.N.P. Choudhary have not responded to correspondence about this retraction.

Publisher's Note Springer Nature remains neutral with regard to jurisdictional claims in published maps and institutional affiliations. 